\title{
Optimization and validation of high performance liquid chromatography-ultra violet method for quantitation of metoprolol in rabbit plasma: application to pharmacokinetic studies
}

\author{
Ayesha Yaqoob, Mahmood Ahmad*, Rai Muhammad Sarfraz and Asif \\ Mahmood \\ Faculty of Pharmacy, The Islamia University of Bahawalpur, 63100, Bahawalpur, Punjab, Pakistan
}

*For correspondence: Email: ma786_786@yahoo.com; Tel: +923009682258; Fax: +92629255565

Received: 28 April 2016

Revised accepted: 14 September 2016

\begin{abstract}
Purpose: To develop a sensitive, simple and validated high performance liquid chromatography (HPLC) analytical method for the determination of metoprolol tartrate in rabbit plasma.

Methods: Mobile phase of methanol and $50 \mathrm{mM}$ ammonium dihydrogen phosphate solution (50:50) at pH 3.05 was used for separation of metoprolol on BDS hypersil C18 column at a wavelength of $223 \mathrm{~nm}$. Flow rate and retention time were $0.6 \mathrm{~mL} / \mathrm{min}$ and $7.4 \mathrm{~min}$, respectively. For pharmacokinetic study, rabbits were given an oral dose of $8 \mathrm{mg} / \mathrm{kg}$ of metoprolol in solution form. Blood samples were taken from jugular vein of the rabbits after drug administration and analysed by HPLC.

Results: Separation of metoprolol was not interfered with other components in plasma. The calibration curve was linear in the range of $25-1000 \mathrm{ng} / \mathrm{mL}\left(r^{2}=0.997\right)$. Lower limits of detection $(L L O D)$ and quantitation (LLOQ) were 8.87 and $25 \mathrm{ng} / \mathrm{mL}$, respectively. Relative standard deviation (RSD) of intraday and inter-day precision was $<14.27$ and $7.61 \%$, respectively. Relative error of accuracy was between 4.85 and $14.37 \%$. Maximum plasma concentration $\left(C_{\max }\right)$, time to maximum plasma concentration $\left(T_{\max }\right)$ and half-life ( $\left.t_{1 / 2}\right)$ after metoprolol oral administration in rabbits were $186.29 \mathrm{ng} / \mathrm{mL}$, $0.50 \mathrm{~h}$ and $2.27 \mathrm{~h}$, respectively.

Conclusion: A simple, accurate and precise HPLC-UV method for metoprolol determination in rabbit plasma has been successfully developed and applied to a pharmacokinetic study.
\end{abstract}

Keywords: HPLC-UV, Metoprolol, Pharmacokinetics, Rabbit plasma, Liquid-liquid extraction, Validation

Tropical Journal of Pharmaceutical Research is indexed by Science Citation Index (SciSearch), Scopus, International Pharmaceutical Abstract, Chemical Abstracts, Embase, Index Copernicus, EBSCO, African Index Medicus, JournalSeek, Journal Citation Reports/Science Edition, Directory of Open Access Journals (DOAJ), African Journal Online, Bioline International, Open-J-Gate and Pharmacy Abstracts

\section{INTRODUCTION}

Metoprolol tartrate is a selective $\beta 1$-adrenergic blocking agents used for management of angina pectoris and treatment of mild to moderate hypertension. Metoprolol is supplied as a racemic mixture of $S$ and $R$ enantiomers. Metoprolol is absorbed up to $95 \%$ but undergoes intensive first pass metabolism after oral administration with bioavailability of 40 to $50 \%$. It has half-life of $3-7 \mathrm{~h}$. Time to reach peak plasma concentration ( $\left.T_{\max }\right)$ is $1-2 \mathrm{~h}$ in human $[1,2]$.

Selective $\beta 1$ activity of metoprolol is proportional to its plasma concentration thus sensitive method of analysis is required for its quantification in plasma. Several HPLC methods are available for 
Metoprolol quantification in plasma, urine and pharmaceuticals [3-6]. Most of them used mass spectrometer and florescent detector. A few of those methods used ultraviolet (UV) detectors. Present HPLC method utilizes UV detector as it is easily available, affordable and convenient and requires less maintenance [7-10]. Liquid-liquid extraction, solid-phase micro-extraction and solid-phase extraction are commonly used for the preparation of biological samples. Most of these methods require various steps for the extraction of metoprolol from blood samples [11,12]. Aim of present study was to develop a sensitive, precise, accurate and simple HPLC-UV method for metoprolol determination in plasma and investigate its application for pharmacokinetic study in rabbits.

\section{EXPERIMENTAL}

\section{Materials}

Metoprolol tartrate was a gift from Acto Laboratories Limited, Pakistan. HPLC grade acetonitrile and methanol were purchased from Merck (Germany). Analytical grade dichloromethane was purchased from Fisher Scientific (UK). Ammonium dihydrogen phosphate was purchased from AppliChem (Germany). Ortho phosphoric acid (analytical grade) was procured from Merck (Germany). Distilled water was freshly prepared on a distillation plant (WDA/4 $\mathrm{R} \& \mathrm{M}$, England). Microfilters of 0.45 micron were purchased from Millipore (Merck, Germany). All other chemicals and reagents used were of analytical grade.

\section{Method development}

\section{Instrumentation and chromatographic conditions}

HPLC apparatus used in present study was from Agilent Technologies series 1100 (USA) with a pump and variable wavelength detector (VWD). Chromatographic data was processed by computerized integration software hp ChemStation. Chromatographic separation was achieved on BDS hypersil C18 column (250 x $4.6 \mathrm{~mm}$, particle size $5.0 \mu \mathrm{m}$, Thermo electron, USA). . During optimization of chromatographic conditions a number of mobile phases were tested comprising of various ratios of acetonitrile, methanol, water and buffer solutions [7]. Buffer solutions of ammonium dihydrogen phosphate, potassium dihydrogen phosphate, disodium hydrogen phosphate, ammonium acetate, sodium dihydrogen phosphate were used in concentrations of 25, 50, 100 and $250 \mathrm{mM}$ with methanol and acetonitrile in order to achieve an optimum separation of metoprolol $[3,5,6]$. Wavelength for maximum absorbance was confirmed on UV-Visible spectrophotometer (IRMCO, U2020) for $10 \mu \mathrm{g} / \mathrm{mL}$ solution of metoprolol in respective mobile phases. The $\mathrm{pH}$ of mobile phase was altered within $2.5-8.0$ using orthophosphoric acid. Finally, mobile phase consisting of Methanol and $50 \mathrm{mM}$ ammonium dihydrogen phosphate solution in ratio of 50:50 at $\mathrm{pH} 3.05$ was used. The overall chromatographic conditions are summarized in Table 1.

Table 1: Optimized chromatographic conditions

\begin{tabular}{ll}
\hline Chromatographic parameter & $\begin{array}{l}\text { Optimized } \\
\text { conditions }\end{array}$ \\
\hline Flow rate & $0.6 \mathrm{~mL} / \mathrm{min}$ \\
Wavelength & $223 \mathrm{~nm}$ \\
Injection volume & $20 \mathrm{\mu L}$ \\
Retention time & $7.4 \mathrm{~min}$ \\
Temperature & $25^{\circ} \mathrm{C}$ \\
Pressure & $108-116$ bars \\
& Methanol and 50 \\
Mobile phase & mM ammonium \\
& dihydrogen \\
$\mathrm{pH}$ & phosphate $50: 50$ \\
\hline
\end{tabular}

\section{Mobile phase preparation}

Solution of ammonium dihydrogen phosphate (50 $\mathrm{mM}$ ) was prepared in fresh distilled water and combined with methanol in ratio of 50:50. The $\mathrm{pH}$ of mixture was adjusted to 3.05 by orthophosphoric acid while monitoring with a $\mathrm{pH}$ meter (WTW pH 300, Germany). Prepared mobile phase was then filtered through $0.45 \mu \mathrm{m}$ Millipore filter by vacuum filtration assembly (Rotary Vane Pump ILMVAC, Germany).

\section{Stock solution}

Stock solution of metoprolol was prepared in concentration of $1 \mathrm{mg} / \mathrm{mL}$ in filtered mobile phase. Serial dilutions were prepared in mobile phase from that stock solution during process of achieving symmetric peaks of drug. For spiking of rabbit plasma, both of stock solution and serial dilutions of metoprolol were prepared in filtered distilled water. Stock solutions were prepared on daily basis.

\section{Plasma spiking}

Blank blood was obtained from the jugular vein of the white albino rabbits. Plasma was separated by centrifugation. Blank Plasma was stored at $20{ }^{\circ} \mathrm{C}$ in order to use during optimization and validation of HPLC method. Blank plasma (0.5 
$\mathrm{mL}$ ) was spiked with $0.5 \mathrm{~mL}$ of serial dilutions of metoprolol (in filtered distilled water) to produce the plasma concentrations of $1000,750,500$, $300,100,50$ and $25 \mathrm{ng} / \mathrm{mL}$ for construction of calibration curve.

\section{Liquid-liquid extraction for plasma samples preparation}

Single step, Liquid-liquid extraction method was used for preparation of plasma samples for HPLC analysis. For extraction of metoprolol, 1 $\mathrm{mL}$ spiked plasma was taken in $12 \mathrm{~mL}$ glass centrifuge tube along with $100 \mu \mathrm{L}$ of $2 \mathrm{~N} \mathrm{NaOH}$ solution and mixed on a vortex mixer (Seouline BioScirnce, Korea) for $5 \mathrm{~s}$. Dichloromethane (6 $\mathrm{mL}$ ) as extracting solvent) was added and mixed immediately for $5 \mathrm{~min}$ in vortex mixer at speed of $1200 \mathrm{rpm} / \mathrm{min}$. After mixing, the mixture was centrifuged for $5 \mathrm{~min}$ at a speed of $5000 \mathrm{rpm}$. The lower organic phase of dichloromethane was separated carefully and transferred to another glass test tube and evaporated under a gentle stream of nitrogen at $40{ }^{\circ} \mathrm{C}$ on sample concentrator. After drying, the residue was reconstituted with $200 \mu \mathrm{L}$ of mobile phase and mixed on vortex mixer for $1 \mathrm{~min}$ at a speed of $2500 \mathrm{rpm} / \mathrm{min}$. $20 \mu \mathrm{L}$ of sample was injected into HPLC system by using $100 \mu \mathrm{L}$ glass syringe in fixed-loop injector.

\section{Validation of method}

Validation in present study was performed by determination of linearity, lower limit of detection (LLOD), lower limit of quantitation (LLOQ), accuracy and precision according to standards of FDA's guidance for industry for bioanalytical method validation [13].

\section{Linearity and calibration}

Linearity of an HPLC method is its ability to obtain peak area of drug in direct proportion to the drug concentration. For construction of calibration curve spiked plasma in concentration range of $25-2000 \mathrm{ng} / \mathrm{mL}$ was extracted by following the procedures stated above and assayed. Calibration curve was prepared by plotting area of metoprolol peaks in chromatograms against concentration of drug in spiked plasma. Linearity was established by regression analysis of calibration curve.

\section{Precision and accuracy}

Precision and accuracy was determined by repeatability and intermediate precision. Precision and accuracy of this method was evaluated at three different levels i.e. 100, 300 and $500 \mathrm{ng} / \mathrm{mL}$. Dilutions were prepared by using stock solution $(1 \mathrm{mg} / \mathrm{mL})$ of metoprolol in water.

For repeatability (intra-day precision) five replicates of three concentrations were analyzed in a single day. For intermediate precision (interday precision) single samples of three different concentrations were analysed for three days [4]. Precision was calculated as percentage of relative standard deviation (RSD, \%). Accuracy was calculated as a percentage of relative error (RE, \%) [8].

$$
\begin{aligned}
& \text { Precision }=\operatorname{RSD}(\%)=\left\{\left(\mathrm{SD} / \mathrm{C}_{1}\right)\right\} 100 \ldots \ldots . . .(1) \\
& \text { Accuracy }=\operatorname{RE}(\%)=\left\{\left(\mathrm{C}_{1}-\mathrm{C}_{0}\right) / \mathrm{C}_{0}\right\} 100 \ldots \ldots . .(2)
\end{aligned}
$$

where $C_{0}$ is concentration added, $C_{1}$ the concentration found and SD is standard deviation.

\section{Sensitivity}

Sensitivity of HPLC method was established by determining its lower limit of detection (LLOD) and lower limit of quantitation (LLOQ). LLOQ is the minimum concentration of drug that can be quantitated with acceptable precision and accuracy (i.e., RSD and RE < $20 \%$ ) [14,15] whereas LLOD is concentration that can be detected but not quantitated.

Determination of LLOQ and LLOD was done on the basis of signal to noise ratio. LLOD and LLOQ are the drug plasma concentrations at which signal/noise is equal to 3 and 10 , respectively. This method is only applicable for procedures where noise is present in base line and where lowest concentration of drug in chromatogram can be distinguished from chromatogram of blank plasma. In present case, both conditions were fulfilled. Signal to noise ratio can be obtained from integration system and can also be measured manually. In the present study, signal to noise ratio was calculated manually. An example of measurement of noise and signal manually is shown in Figure 1.

LLOD was calculated by using following equation $[16,17]$.

$\operatorname{LLOD}=(3 \mathrm{~N} / \mathrm{S}) \mathrm{C}_{1}$

where $\mathrm{C}_{1}$ is the concentration found, $\mathrm{N}$ is noise and $S$ is signal. 

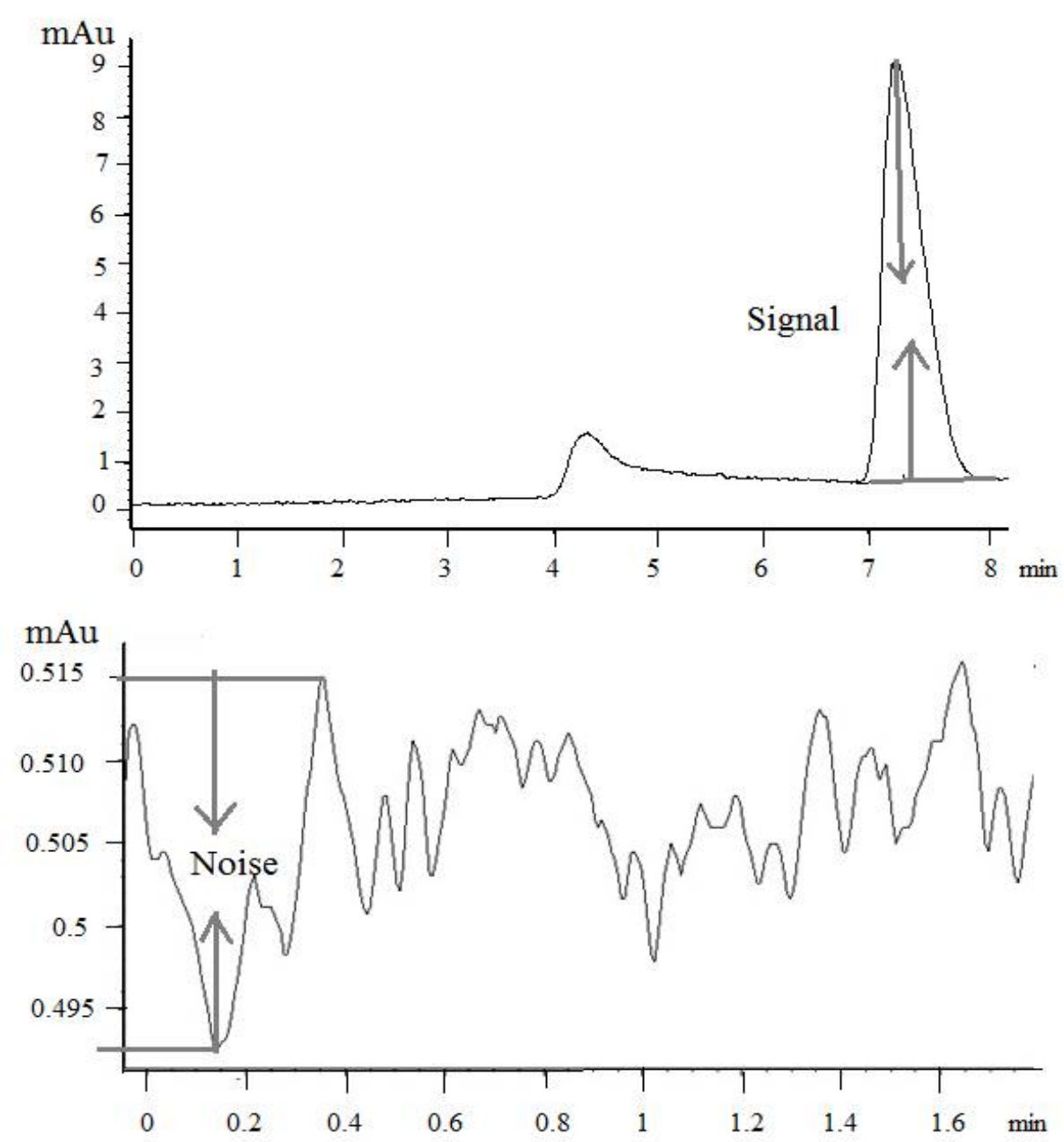

Figure 1: Measurement of signal and noise manually

\section{Application of developed method to pharmacokinetic studies}

Developed method was applied for quantification of metoprolol in rabbits. The study was approved by Pharmacy Research Ethics Committee (PREC), the Islamia University of Bahawalpur, Pakistan, (Ref. No. 61-2013/PERC). The study was performed in accordance with international guidelines for animal studies [18]. Rabbits $(n=5)$ were fasted overnight but were given free access to water. Rabbits were given a dose of $8 \mathrm{mg} / \mathrm{kg}$ metoprolol in form of oral solution and blood sample were taken at time points of $0,0.5,1,2,4$ and $8 \mathrm{~h}$. Plasma from blood was separated by centrifugation and stored at $-70{ }^{\circ} \mathrm{C}$ in an ultrafreezer (Sanyo, Japan). Before analysis on HPLC, plasma samples were allowed to warm at room temperature and then extracted by following same procedure as adopted for spiked plasma. Metoprolol concentrations in rabbit plasma were calculated from the calibration curve. Pharmacokinetic parameters were calculated for each subject using scientific application package, Kinetica ${ }^{\circledR}$ version 5.0 (Thermo Fisher Scientific, USA).

\section{RESULTS}

\section{Optimized method}

A number of mobile phases were tested comprising of various ratios of acetonitrile, methanol, water and buffer solutions. Finally, the mobile phase consisting of methanol and $50 \mathrm{mM}$ ammonium dihydrogen phosphate was selected because of symmetry of drug peak, sensitivity and reasonable retention time. Representative chromatograms are shown in Figure 2. The figure showed that separation of metoprolol peak was not interfered by other components in plasma. 

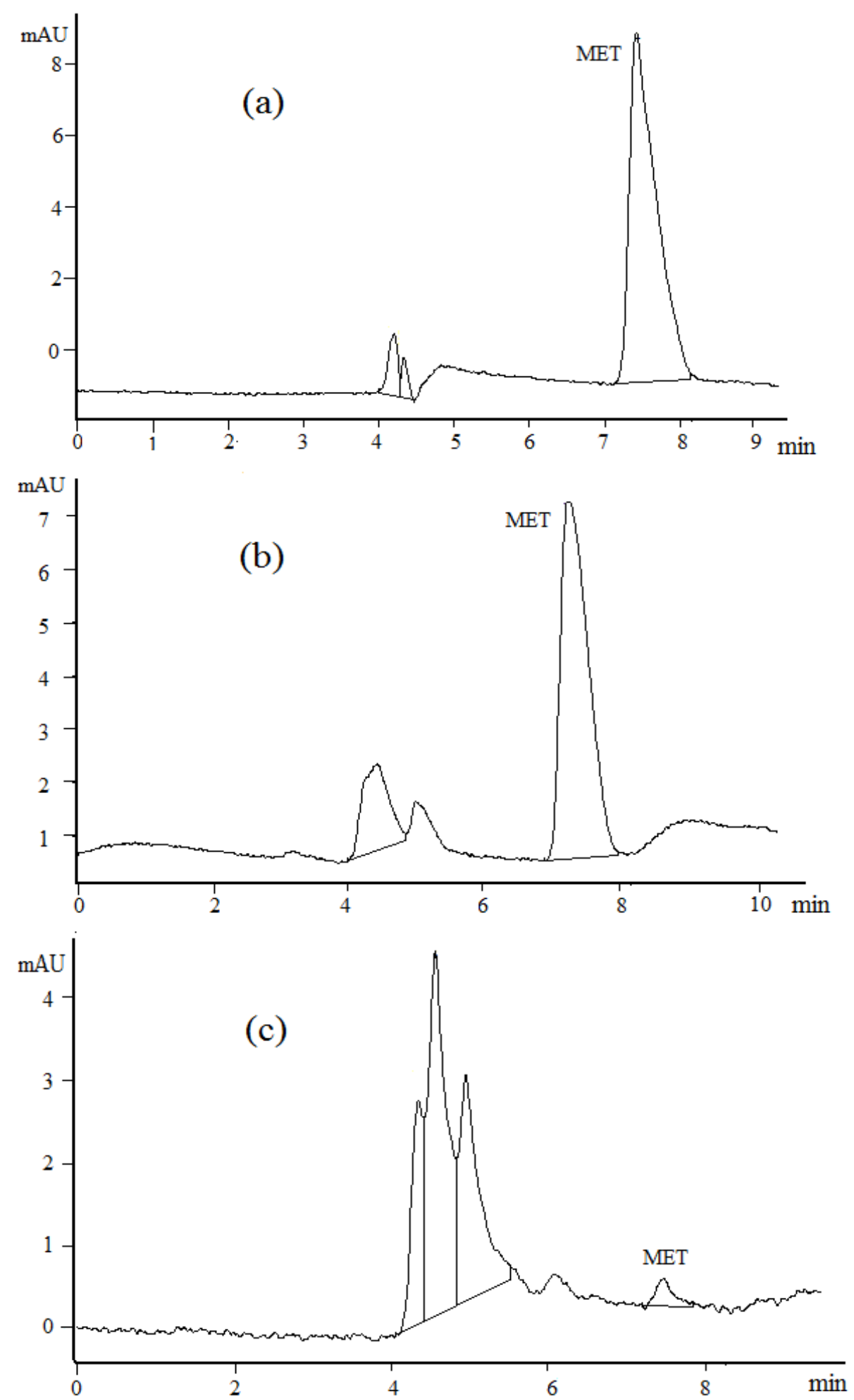

Figure 2: HPLC chromatograms of (a) pure metoprolol (MET) in mobile phase; (b) rabbit plasma spiked with metoprolol and (c) plasma samples taken from rabbits after treatment with $8 \mathrm{mg} / \mathrm{kg}$ oral dose of metoprolol

\section{Linearity of calibration curve}

Calibration curve was found linear in range of 25 - $1000 \mathrm{ng} / \mathrm{mL}$ with a correlation coefficient $(R)$ of 0.997 . The slope of the calibration curve was 0.1815 and regression equation was $y=0.1815$ $x+1.3466$.

\section{Precision and accuracy}

Based on the results shown in Table 2, precision (RSD) and accuracy (RE) were in the range of 12.85 to $14.27 \%$ and 6.32 to $7.61 \%$, respectively. 
Application of developed method to pharmacokinetic studies in rabbits

Plasma concentration versus time profile of metoprolol after oral administration is shown in Figure 3. Non-compartmental approach was used for calculation of pharmacokinetic parameters. Pharmacokinetic parameters are given in Table 4. Half-life of metoprolol ( $(t / 2)$ was
$2.27 \pm 0.13 \mathrm{~h}, \mathrm{AUC}_{0-\alpha}$ was $689.33 \pm 535.39$ $\mathrm{ng} / \mathrm{mL} / \mathrm{h}$ and $\mathrm{C}_{\max }$ was $186.29 \pm 15.86 \mathrm{ng} / \mathrm{mL}$.

\section{Sensitivity}

LLOD as calculated from signal to noise ratio is given in Table 3. LLOD was found $8.87 \mathrm{ng} / \mathrm{mL}$ whereas LLOQ was $25 \mathrm{ng} / \mathrm{mL}$.

Table 2: Precision and accuracy of the proposed method for metoprolol in rabbit spiked plasma $(n=5)$

\begin{tabular}{|c|c|c|c|c|}
\hline $\begin{array}{l}\text { Concentration } \\
\text { added }(\mathrm{ng} / \mathrm{mL})\end{array}$ & $\begin{array}{c}\text { Mean } \\
\text { concentration } \\
\text { found ( } \mathrm{ng} / \mathrm{mL})\end{array}$ & SD* $^{*}$ & $\begin{array}{c}\text { Precision } \\
\text { (RSD, \%) }\end{array}$ & $\begin{array}{c}\text { Accuracy } \\
\text { (RE, \%) }\end{array}$ \\
\hline \multicolumn{5}{|l|}{ Intra-day $(n=5)$} \\
\hline 100 & 95.15 & 12.96 & 13.62 & 4.85 \\
\hline 300 & 262.49 & 37.45 & 14.27 & 12.50 \\
\hline 500 & 505.96 & 64.97 & 12.85 & 1.99 \\
\hline \multicolumn{5}{|l|}{ Inter-day $(n=3)$} \\
\hline 100 & 86.87 & 5.49 & 6.32 & 13.13 \\
\hline 300 & 256.90 & 19.55 & 7.61 & 14.37 \\
\hline 500 & 454.24 & 30.78 & 6.78 & 9.15 \\
\hline
\end{tabular}

*SD = standard deviation

Table 3: LLOD results

\begin{tabular}{ccccc}
\hline S/N & $\begin{array}{c}\text { Concentration } \\
\text { spiked }\end{array}$ & Noise/signal & $\begin{array}{c}\text { Concentration found } \\
\text { (ng/mL) }\end{array}$ & LLOD \\
\hline 1 & $100 \mathrm{ng}$ & 0.0331 & 93.10 & 9.24 \\
2 & $100 \mathrm{ng}$ & 0.0386 & 70.51 & 8.16 \\
3 & $100 \mathrm{ng}$ & 0.0318 & 97.91 & 9.33 \\
4 & $100 \mathrm{ng}$ & 0.0287 & 102.53 & 8.82 \\
5 & $100 \mathrm{ng}$ & 0.0285 & 99.54 & 8.49 \\
6 & $100 \mathrm{ng}$ & 0.0285 & 107.30 & 9.14 \\
& & Mean LLOD value & & $\mathbf{8 . 8 7}$ \\
\hline
\end{tabular}

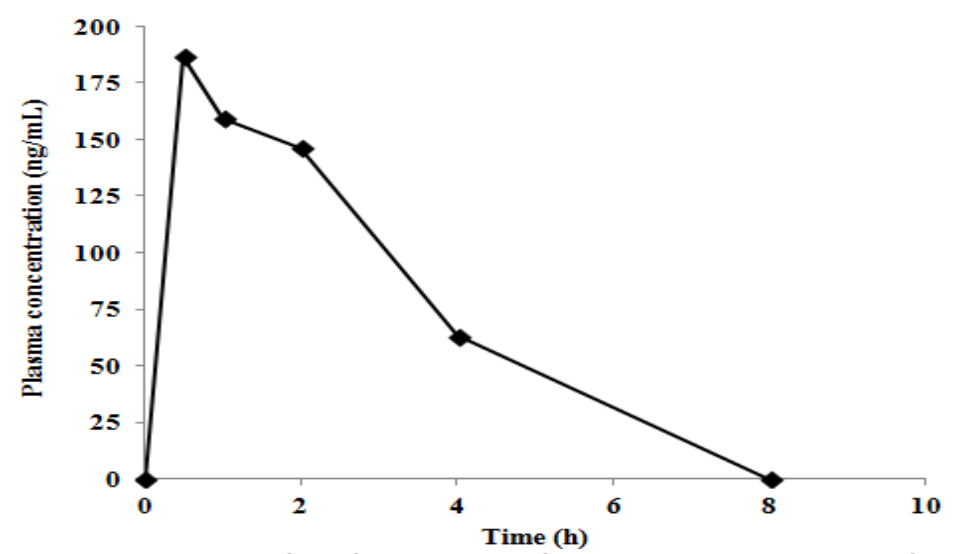

Figures 3: Plasma concentration time profile of metoprolol after administering a dose of $8 \mathrm{mg} / \mathrm{kg}$ in rabbits

Table 4: Pharmacokinetic parameters for metoprolol in rabbits after oral administration of $8 \mathrm{mg} / \mathrm{kg}$ $($ mean $\pm S D, n=5)$

\begin{tabular}{|c|c|c|c|c|c|}
\hline $\begin{array}{l}T_{\max } \\
\text { (h) }\end{array}$ & $C_{\max }(n g / m L)$ & $\begin{array}{c}\mathrm{AUC}_{0-\mathrm{t}} \\
(\mathrm{ng} / \mathrm{mL} / \mathrm{h})\end{array}$ & $\begin{array}{c}\text { AUC }_{0-\alpha} \\
(\mathrm{ng} / \mathrm{mL} / \mathrm{h})\end{array}$ & MRT (h) & $t^{1} 1 / 2(h)$ \\
\hline $\begin{array}{l}0.50 \pm \\
1.06\end{array}$ & $186.29 \pm 15.86$ & $\begin{array}{c}482.92 \pm \\
131.61\end{array}$ & $\begin{array}{c}689.33 \pm \\
535.39\end{array}$ & $3.46 \pm 0.46$ & $2.27 \pm 0.13$ \\
\hline
\end{tabular}

$T_{\max }$ : time to reach maximum plasma concentration, $C_{\max }$ : maximum plasma concentration, $A \cup C_{0-t}$ : area under plasma concentration time curve from 0 to $8 \mathrm{~h}, A \cup C_{0-\alpha}$ : area under the curve from $0 \mathrm{~h}$ to infinity, MRT : mean residence time, $t^{1} \frac{1}{2}$ : Half- life of drug 


\section{DISCUSSION}

The quality of developed HPLC method depends on purpose of separation of analyte, ease in extraction, sensitivity, precision and accuracy, time of analysis and cost of chemicals. Selection of the right mobile phase for separation of metoprolol on column was dependent on peak symmetry and a reasonable retention time so that the drug peak should not interact with plasma peaks. During pH setting of mobile phase it was observed that higher $\mathrm{pH}$ provided less sensitivity and asymmetrical peaks. Thus, a $\mathrm{pH}$ range of $2.5-4.0$ was selected for the investigation. From the number of buffers used, ammonium dihydrogen phosphate and potassium dihydrogen phosphate provided the required symmetry of peaks. The main problem in method development was height and area of drug peak in chromatogram. Initially combination of ammonium dihydrogen phosphate buffer with acetonitrile provided required symmetry and sensitivity. However, retention time in that method was short. Due to that short retention time, plasma peak interfered with metoprolol. Further trials were performed for ammonium dihydrogen phosphate and methanol combination. Finally, the selected mobile phase provided the required sensitivity and chromatographic separation with reasonable retention time with total run time of $10 \mathrm{~min}$.

During optimization of chromatographic conditions, temperature was changed between 25 to $40{ }^{\circ} \mathrm{C}$. Changes in temperature did not affect the resolution of peak. But decrease in the column pressure was observed with increase in temperature.

Metoprolol is very soluble in water and is freely soluble in alcohol, chloroform and dichloromethane, thus selection of extracting solvent was difficult. During process of liquidliquid extraction, a number of methods were employed for effective plasma extraction by using n-hexane, chloroform and dichloromethane as extracting solvents. Finally, dichloromethane was selected for maximum extraction. During extraction procedure, solution of $2 \mathrm{~N} \mathrm{NaOH}$ was added to neutralize dichloromethane. The calibration curve constructed by spiking rabbit plasma with metoprolol was linear in the range of $25-2000 \mathrm{ng} / \mathrm{mL}$. In the present HPLC method, precision and accuracy were both $<15 \%$ which are in compliance with FDA criteria [13].

\section{CONCLUSION}

A sensitive and simple HPLC-UV method has been developed and validated for metoprolol determination in rabbit plasma. A single-step liquid-liquid extraction procedure for sample preparation was adopted and metoprolol peak separation was not interfered with other components of plasma. The developed method has been successfully applied to pharmacokinetic studies of metoprolol in rabbits.

\section{DECLARATIONS}

\section{Acknowledgement}

The authors are thankful to Higher Education Commission (HEC) of Pakistan for providing financial support for this study in the form of a scholarship to Ayesha Yaqoob.

\section{Conflict of Interest}

No conflict of interest associated with this work.

\section{Contribution of Authors}

The authors declare that this work was done by the authors named in this article and all liabilities pertaining to claims relating to the content of this article will be borne by them.

\section{REFERENCES}

1. Martindale W. Martindale: the complete drug reference. Ed 36. Pharmaceutical Press: London, UK; 2009.

2. Katzung BG, Masters SB, Trevor AJ. Basic \& Clinical Pharmacology. Vol 8. Lange Medical Books/McGrawHill: New York, USA; 2004.

3. Krishnaiah $Y$, Karthikeyan $R$, Satyanarayana V. A threelayer guar gum matrix tablet for oral controlled delivery of highly soluble metoprolol tartrate. Int J Pharm 2002; 241: 353-366.

4. Yilmaz B, Meral K, Asci A, Ornganer Y. Determination of metoprolol in pure and pharmaceutical dosage forms by spectrofluorometry and high performance liquid chromatography. Chem Ind Chem Eng Q 2011; 17: 2531.

5. Padmalatha Devi K, Ranga Rao K, Baveja S, Leemann $T$, Dayer $P$. Determination of alprenolol and metoprolol in plasma by column liquid chromatography. J Chromatogr B 1988; 434: 265-270.

6. Al-Saidan S, Krishnaiah Y, Satyanarayana V, Bhaskar P, Karthikeyan R. Pharmacokinetic evaluation of guar gumbased three-layer matrix tablets for oral controlled delivery of highly soluble metoprolol tartrate as a model drug. Eur J Pharm Biopharm 2004; 5: 697-703.

7. Yilmaz B, Asci A, Arslan S. Determination of metoprolol in human plasma and urine by high-performance liquid chromatography with fluorescence detection. J Sep Sci 2010; 33: 1904-1908. 
8. Xu T, Bao S, Geng P, Luo J, Yu L, Pan P, Chen Y, Hu G. Determination of metoprolol and its two metabolites in human plasma and urine by high performance liquid chromatography with fluorescence detection and its application in pharmacokinetics. J Chromatogr B 2013; 937: 60-66.

9. Albers S, Elshoff JP, Volker C, Richter A, Laer S. HPLC quantification of metoprolol with solid-phase extraction for the drug monitoring of pediatric patients. Biomed Chromatogr 2005; 19: 202-207.

10. Aqil M, Ali A, Ahad A, Sultana $Y$, Najmi A, Saha N. A validated HPLC method for estimation of metoprolol in human plasma. Acta Chromatogr 2007; 19, 130-140.

11. Saleem K, Ali I, Kulsum U, Aboul-Enein HY. Recent developments in HPLC analysis of $\beta$-blockers in biological samples. J Chromatogr Sci 2013; 30: 1-12.

12. Harrison $P$, Tonkin A, McLean A. Simple and rapid analysis of atenolol and metoprolol in plasma using solid-phase extraction and high-performance liquid chromatography. J Chromatogr B 1985; 339: 429-433.

13. Food and Drug Administration, Guidance for industry: bioanalytical method validation 2001. Available from: www. fda. gov/ downloads/ drugs/ guidancecomplian ceregulatoryinfo rmation/ guidances/ ucm368107.pdf, 2007.
14. Pervaiz F, Ahmad M, Minhas MU, Sohail $M$. Development and Validation of Reverse Phase High Performance Chromatography Method for Determination of Olanzapine in Microsample Rat Plasma: Application to Preclinical Pharmacokinetic Study. Trop J Pharm Res 2015; 14: 141-147.

15. Shrivastava A, Gupta VB. Methods for the determination of limit of detection and limit of quantitation of the analytical methods. Chronicles of Young Scientists 2011; 2: 21-25.

16. Minhas MU, Ahmad $M$, Sohail $M$, Siddique $F$. Development and Optimization of Fast and New Reversed-Phase HPLC Method for Analysis of 5Fluorouracil in Human and Rabbit Plasma. Pak Vet $\mathrm{J}$, 2014; 35: 71-75.

17. Barrett B, Holcapek M, Huclova J, Borek-Dohalsky V, Fejt $P$, Nemec B, Jelinek I. Validated HPLC-MS/MS method for determination of quetiapine in human plasma. J Pharmaceut Biomed, 2007; 44: 498-505.

18. National Institutes of Health. Guide for the care and use of laboratory animals. Washington: National Academies; 2011. Available from: http://grants.nih.gov/grants/olaw/Guide-for-the-careanduse-of-laboratory-animals. pdf. 